\title{
Effect of mineral filler additives on flammability, processing and use of silicone-based ceramifiable composites
}

\author{
Rafał Anyszka ${ }^{1,5}$ (D) Dariusz M. Bieliński ${ }^{1}$ - Zbigniew Pędzich ${ }^{2} \cdot$ \\ Grzegorz Parys $^{3}$ - Przemysław Rybiński ${ }^{4}$ - Magdalena Zarzecka- \\ Napierała $^{2}$ - Mateusz Imiela ${ }^{1}$ - Tomasz Gozdek ${ }^{1}$ - Mariusz Siciński ${ }^{1}$. \\ Michał Okraska' ${ }^{1}$ Magdalena Ziąbka ${ }^{2} \cdot$ Magdalena Szumera $^{2}$ \\ Received: 2 September 2016/Revised: 28 April 2017/Accepted: 4 July 2017 / \\ Published online: 24 July 2017 \\ (C) The Author(s) 2017. This article is an open access publication
}

\begin{abstract}
The aim of this work is to describe the changes in the properties of ceramifiable silicone rubber-based composites caused by the incorporation of novel alternative minerals in comparison to other popular, widely utilized fillers. $\mathrm{TiO}_{2}$, calcined kaolin and calcium-based minerals mix (CbMix) consisting of $\mathrm{CaO}$ (6.26 wt $\%), \mathrm{CaCO}_{3}(26.18 \mathrm{wt} \%)$ and $\mathrm{Ca}(\mathrm{OH})_{2}(67.56 \mathrm{wt} \%)$ have not been considered as a dispersed phase of ceramifiable silicone composites destined for wire covers yet. Mineral fillers: $\mathrm{TiO}_{2}$ (anatase), mica (phlogopite), $\mathrm{CbMix} \mathrm{CaCO}_{3}, \mathrm{Al}(\mathrm{OH})_{3}$, kaolin and calcined kaolin affect the processing and the various properties of silicone rubber-based composites destined for wire covers differently. The propertiesflammability, smoke intensity, micromorphology and mechanical durability after ceramification - are assessed by measuring: the kinetics of vulcanization, stress at different levels of elongation, tensile strength and the elongation at break of the materials. Although the curing process of the composites is disturbed by the addition
\end{abstract}

Electronic supplementary material The online version of this article (doi:10.1007/s00289-017-21130 ) contains supplementary material, which is available to authorized users.

Rafał Anyszka

anyszka.rafal@gmail.com; r.p.anyszka@utwente.nl

1 Faculty of Chemistry, Institute of Polymer and Dye Technology, Lodz University of Technology, Łódź, Poland

2 Department of Ceramics and Refractory Materials, Faculty of Material Science and Ceramics, AGH - University of Science and Technology, Kraków, Poland

3 Division of Elastomers and Rubber Technology, Institute for Engineering of Polymer Materials and Dyes, Piastów, Poland

4 Department of Management and Environmental Protection, Jan Kochanowski University, Kielce, Poland

5 Present Address: Chair of Elastomer Technology and Engineering, Department of Mechanics of Solids, Surfaces and Systems (MS3), Faculty of Engineering Technology, University of Twente, Enschede, The Netherlands 
of CbMix, it benefits from an increase in oxygen index value, which reaches $31.4 \%$. What is more, also its flammability parameters measured by cone calorimetry improve, such as the total heat released (THR) reaching $9.3 \mathrm{MJ} / \mathrm{m}^{2}$. Samples containing kaolin and calcined kaolin exhibit the best mechanical properties before ceramification, whereas composites filled with calcium-based powders (CbMix, $\left.\mathrm{CaCO}_{3}\right)$ mechanically display the strongest mineral char after heat treatment, possibly due to a more homogenous micromorphology and the creation of calcium silicates at elevated temperature. Significant amounts of wollastonite, parawollastonite and pseudowollastonite are visible in their structure after ceramification.

Keywords Silicone composite - Cable cover - Ceramization · Ceramification · Mineral filler Fire performance

\section{Introduction}

Although ceramifiable (also called: ceramizable) covers manufacturing technology has been known since the beginning of the 1980s, the demand for those materials increased only at the end of the 20th century when the need for maintaining integrity of fire-alarm wiring in fire was described in the US National Fire Alarm Code (NFPA 72-1999; USA). That period saw also the development of various standards concerning circuit integrity in places of increased risk of fire were developed all around the world. And presently, ceramifiable composites are widely applied in fire pumps, emergency feeder cables, ventilating fans, exit lighting and elevators that continue to operate in case of fire event, especially in tall buildings, hospitals, shopping malls and other high-risk buildings [1]. Although the idea of using elevators for evacuation in case of fire is still treated warily [2], the need for efficient evacuation of people (especially elderly or disabled) from tall buildings necessitates the use of elevators that guarantee the safety of power delivery.

Ceramifiable silicone rubber-based composites are nowadays commonly and widely used in cable industry as a covering material for copper core protection in case of fire. These composites consist of a silica reinforced silicone rubber matrix [3] and a mixture of mineral fillers, which often includes low softening point temperature glassy frit promoting ceramification process as well as refractory thermally stable fillers. In the presence of flame and elevated temperature, ceramifiable composites are able to create a mechanically resistant and porous ceramic structure maintaining the integrity of an electric circuit for $120 \mathrm{~min}$, and even longer. Those materials have become very popular in cable industry due to their ability to protect copper wire from extensive heat during fire as well as their high flame retardancy. Ghane et al. indicated that presence of ceramic layer decreases also heat transfer through flexible materials [4]. The mechanisms of their ceramification, especially the involvement of various types of fillers, have been described in the literature on the subject by Hamdani-Devarennes et al. who compared calcium and aluminum-based fillers as main-refractory fillers for ceramifiable composites. They discovered that calcium-based fillers could provide stronger ceramic structure under 
heat treatment than aluminum-based fillers [5-7] and provided a state-of-the-art summary on the subject of ceramifiable composites [8]. Mansouri et al. [9-11] and Hanu et al. [12-14] also conducted outstanding research concerning ceramifying silicone composites. Wang J. et al. developed a glassy frit facilitating ceramification of remarkably low softening point temperature of $400{ }^{\circ} \mathrm{C}$ [15]. Whereas Xiong et al. proposed a solid-state sintering mechanism as an explanation of highly loaded silicone composites ceramification [16]. Many studies describe effects of incorporation of different additives on properties of ceramifiable silicone composites, such as organic and mineral fibers [17], carbon fibers [18], organo-modified montmorillonites (O-MMT) [19], cenospheres covered with iron [20, 21] or silsesquioxanes $[22,23]$. Final properties of the ceramic structure strongly depend on ceramification conditions and these may vary considerably in case of an actual fire event. Thus, it is crucial to develop composite materials which are able to ceramify successfully under a wide range of thermal conditions, taking into account such variables as the temperature, heating rate, type of an atmosphere, possible external stress and the effect of thermal conductivity of inner copper core, which plays a significant role in fire spreading along the cable [24].

It is well-known that high elasticity and electric insulation is required for materials destined for wire covers, what necessitates the usage of polymer, especially elastomer based materials, which on the whole exhibit a relatively low thermal stability and limited resistance to fire [25-27]. Alvares et al. described flammability of rubber materials from the point of view of their massive utilization as materials for vehicle production (tires, conveyor belts, and electrical power cable insulation) [28]. Extensive research in the field of elastomers and cross-linked elastomers thermal stability and flammability has revealed the pressing need for the incorporation of flame retardants into the elastomer matrix to assure their satisfactory utilization and performance [29-31]. This in turn requires the development of ever new flame retardant systems. On the other hand, numerous efficient flame retardants are becoming forbidden due to the emission of corrosive or toxic products. Consequently, so-called passive flame retardants are growing in popularity, such as for instance hydroxides, intumescent systems [32] or char forming agents [33]. Ceramification can be described as an enhanced mechanism of strong, barrier mineral char formation. The resulting char prevents the composite from oxygen diffusion into bulk material and from diffusion of fuel to the burning zone. Moreover, ceramifiable composites can be developed not only on the basis of silicone rubber but also more common, organic polymers. For example, the research conducted by Wang et al. showed that the ceramification mechanism can be employed to increase polyethylene flame retardancy [34], whereas Shanks et al. described the application of additives promoting ceramification for poly(vinyl acetate)-based [35] and unsaturated polyester-based [36] fire barrier composites. Recent studies describing properties of ceramifiable styrene-butadiene rubber (SBR) [37], poly(ethylene-vinyl acetate) (EVA) [38] and EVA/PDMS-based [39] composites have revealed that in spite of its short history, ceramification is regarded by many researchers as a perspective flame retardancy mechanism. One of the most significant factors contributing to its widespread recognition (as a flame retardancy mechanism) is the high amount of mineral fillers required for ceramifiable 
composites to trigger an effective ceramification process. However, high content of mineral fillers can negatively affect rheological properties of the mixes and mechanical properties of the composites.

Ceramification can be performed in several ways: (1) Production of amorphous silica during thermooxidative degradation of silicone matrix, which adsorbs on the surface of refractory fillers creating mineral bridges between refractory filler particles. (2) Sintering of mineral filler particles due to condensation of hydroxyl groups present on their surface $[16,40]$. (3) Synthesis of new mineral phases as a result of reaction between refractory filler particles and silica produced caused by thermooxidative degradation of silicone matrix. (4) Creation of physical bridges between particles of thermally stable minerals by a low-temperature softening point, amorphous, fluxing agent (Fig. 1). (5) Creation of silicon oxycarbide ceramic via cross-linking of siloxane macromolecules at elevated temperature with presence of platinum catalyst or cross-linking of macromolecules adsorbed on active filler surface, for example, silica [41].

This study focuses on the effect of unmodified mineral fillers on flammability, smoke emission and ceramification performance of ceramifiable silicone composites taking into account their processability, utilization and mechanical properties prior to fire and heat treatment. It places emphasis on the properties of composites filled with $\mathrm{TiO}_{2}, \mathrm{CbMix}$ and calcined kaolin, which have not been utilized as a dispersed phase for ceramifiable composites yet.

\section{Experimental}

\section{Materials}

High temperature vulcanizable silicone rubber (HTV) containing $0.07 \% \mathrm{~mol} / \mathrm{mol}$ of vinyl groups, produced by Polish Silicones Ltd. (Poland), reinforced with Aerosil

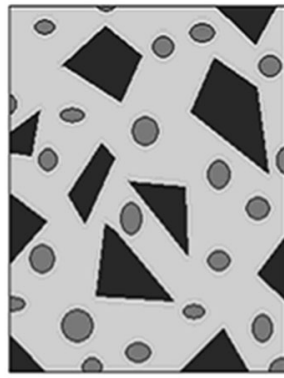

Mineral filler particles

Fluxing agent particles

\section{Silicone rubber matrix}

Fig. 1 Scheme explaining mechanism of ceramification with effect of a fluxing agent 
200 fumed silica (BET specific surface area $175-225 \mathrm{~m}^{2} / \mathrm{g}$; mass loss on drying $\leq 1.5 \%$ ), originated from Evonik Industries (Germany) was used as an elastomer base for the research. Fluxing agent (A 2120), a glassy frit, consist of 7.3\% wt of $\mathrm{CaO}, 25.0 \%$ wt of $\mathrm{Na}_{2} \mathrm{O}, 2.1 \%$ wt of $\mathrm{K}_{2} \mathrm{O}, 4.2 \%$ wt of $\mathrm{Al}_{2} \mathrm{O}_{3}$, and $61.4 \%$ wt of $\mathrm{SiO}_{2}$, with softening point temperature of $T_{\mathrm{s}}=480{ }^{\circ} \mathrm{C}$ (particle size on sieve $\leq 63 \mu \mathrm{m}$ ), originated from Reimbold \& Strick GmbH (Germany) was used. Natural kaolin KOM (particle size distribution $\mathrm{D}_{90}=4.2 \mu \mathrm{m}, \mathrm{D}_{50}=1.3 \mu \mathrm{m}$ and $\mathrm{D}_{10}=0.2 \mu \mathrm{m}$; BET specific surface area $13 \mathrm{~m}^{2} / \mathrm{g}$ ) was originated form Surmin-Kaolin mine (Poland), which is a part of Quarzwerke GmbH group (Germany). Calcined kaolin (Polestar 200R; particle size distribution $>10 \mu \mathrm{m}=10 \% \max ,<2 \mu \mathrm{m}=44 \% \mathrm{~min}$; BET specific surface area $8.5 \mathrm{~m}^{2} / \mathrm{g}$ ) was purchased form Imerys Minerals Ltd (France). Mica-phlogopite (PW 30; particle size distribution $<150 \mu \mathrm{m}=99-100 \%$, $<45 \mu \mathrm{m}=90 \% \min , \mathrm{D}_{50}=18 \mu \mathrm{m}$ ) was purchased from LKAB Minerals (Sweden). Aluminum hydroxide (Martinal OL-107 LEO; particle size distribution $\mathrm{D}_{50}=1.6-1.9 \mu \mathrm{m}$; BET specific surface area $6-8 \mathrm{~m}^{2} / \mathrm{g}$ ) was originated from Martinswerk GmbH (Germany), which is a part of Albemarle Corporation (USA). Calcium-based-technical grade minerals mix (CbMix) consists of $\mathrm{CaO}$ (6.26 wt $\%), \mathrm{CaCO}_{3}(26.18 \mathrm{wt} \%)$ and $\mathrm{Ca}(\mathrm{OH})_{2}(67.56 \mathrm{wt} \%)$ calculated from thermogravimetric analysis (Fig. 6a), (particle size distribution $\mathrm{D}_{50}=3.5-4.0 \mu \mathrm{m}$ ) was purchased from Mercury HM (Poland). Calcium carbonate-technical grade (particle size distribution $\mathrm{D}_{50}=1.5-2.0 \mu \mathrm{m}$ ), was obtained from Minerał Ltd mine (Poland). Titanium oxide (anatase; particle size distribution $\leq 45 \mu \mathrm{m}$ ) was purchased form Sigma Aldrich (USA). 50\% wt. paste of bis(2,4-dichlorobenzoyl) peroxide, used for curing of the studied composite mixes was purchased from Novichem (Poland). All the components were used as received.

\section{Methods}

Surface free energy of the mineral fillers was measured using Krüss K100 tensiometer (Germany) operating in sorption mode with polar (methanol) and nonpolar (hexane) liquids (Table 1). Thermogravimetry (TG) performed along with differential scanning calorimetry (DSC) analysis of the mineral fillers was done by means of Netzsch SPA $449 \mathrm{~F} 3$ device (Germany), with heating rate of $10^{\circ} \mathrm{C} / \mathrm{min}$, under air atmosphere.

Silicone rubber-based mixes (Table 2) were prepared by Brabender-Plasticorder laboratory micromixer (Germany), with the rotor operational speed of $20 \mathrm{rpm}$, during the components incorporation $(5 \mathrm{~min})$ and of $60 \mathrm{rpm}$ speed during mixes homogenization (10 $\mathrm{min})$.

Kinetic of vulcanization of the mixes was measured by means of WG-05 vulcameter (Poland) at $130{ }^{\circ} \mathrm{C}$, directly after mixes preparation and for comparison after a week of conditioning at storage temperature. Mechanical properties of the samples vulcanized directly after preparation were studied by means of Zwick-Roell 1435 instrument (Germany). Stress at 100\% (SE100), 200\% (SE200) and 300\% (SE300) of elongation was determined along with elongation at break (Eb) and tensile strength (TS) of the vulcanizates. Flame retardancy of the composites was determined by oxygen index measurement (OI) according to the PN-ISO 4589-2 
Table 1 Surface free energy of the mineral fillers

\begin{tabular}{llllllll}
\hline Component $(\mathrm{mN} / \mathrm{m})$ & \multicolumn{7}{l}{ Mineral fillers description } \\
\cline { 2 - 8 } & Kaolin & Calcined kaolin & Mica & $\mathrm{Al}(\mathrm{OH})_{3}$ & $\mathrm{CbMix}$ & $\mathrm{CaCO}_{3}$ & $\mathrm{TiO}_{2}$ \\
\hline Polar component & 0.83 & 0.85 & 0.51 & 1.62 & 15.64 & 4.23 & 2.69 \\
Dispersion component & 14.19 & 13.17 & 17.64 & 18.24 & 8.13 & 18.33 & 7.26 \\
Summary & 15.02 & 14.02 & 18.15 & 19.86 & 23.77 & 22.56 & 9.95 \\
\hline
\end{tabular}

Table 2 Composition of the silicone rubber-based mixes

\begin{tabular}{|c|c|c|c|c|c|c|c|}
\hline \multirow[t]{2}{*}{ Component (phr) } & \multicolumn{7}{|c|}{ Sample description } \\
\hline & $\mathrm{KAO}$ & $\mathrm{C}-\mathrm{KAO}$ & MIC & $\mathrm{AOH}$ & $\mathrm{CAO}$ & CACO & TIO \\
\hline Silicone rubber & 100 & 100 & 100 & 100 & 100 & 100 & 100 \\
\hline Fumed silica & 41 & 41 & 41 & 41 & 41 & 41 & 41 \\
\hline Fluxing agent & 20 & 20 & 20 & 20 & 20 & 20 & 20 \\
\hline Kaolin & 20 & - & - & - & - & - & - \\
\hline Calcined kaolin & - & 20 & - & - & - & - & - \\
\hline Mica & - & - & 20 & - & - & - & - \\
\hline $\mathrm{Al}(\mathrm{OH})_{3}$ & - & - & - & 20 & - & - & - \\
\hline CbMix & - & - & - & - & 20 & - & - \\
\hline $\mathrm{CaCO}_{3}$ & - & - & - & - & - & 20 & - \\
\hline $\mathrm{TiO}_{2}$ & - & - & - & - & - & - & 20 \\
\hline Peroxide paste & 2.2 & 2.2 & 2.2 & 2.2 & 2.2 & 2.2 & 2.2 \\
\hline
\end{tabular}

standard. Moreover, cone calorimetry measurements were done by means of Fire Testing Technology Ltd. calorimeter (UK) operating with heating source of $35 \mathrm{~kW} /$ $\mathrm{m}^{2}$ placed $25 \mathrm{~mm}$ from the samples surface. Smoke intensity during burning was calculated according to the PN-91/K-02501 standard, in which intensity of defined lamp light beam transmittance intensity, during 4 min of burning is calculated as $1 \mathrm{x}$ - $240 \mathrm{~s}$. This test divides materials into three groups: exhibiting low intensity of smoking D1 >18,000 $(\mathrm{l} \times \mathrm{s})$, medium intensity of smoking $9000(\mathrm{l} \times \mathrm{s})<\mathrm{D} 2 \leq 18,000$ $(1 \times s)$ and high intensity of smoking D3 $\leq 9000(1 \times s)$.

Micromorphology of the composite samples was examined before and after ceramification by means of scanning electron microscopy (SEM) Nova Nano 200 FEI (United Kingdom).

Qualitative and quantitative analysis of the ceramified samples containing calcium-based fillers (CAO and CACO) was performed by means of X-ray scattering diffractometer-Empyrean Panalytical B. V. (The Netherlands) operating with $60 \mathrm{kV}$ source voltage. Qualitative determination of crystalline phases was done utilizing ICDD database (pseudowollastonite 98-002-6553; b-quartz 98-008-9281 
a-quartz 98-007-7681; $\mathrm{CaO}$ 98-002-6959; albite 98-003-4917; parawollastonite 98-003-0884; cristobalite 98-016-2660; tridymite 98-009-4090). Quantitative analyses were performed by means of the Rietveld refinement procedure.

The samples of the composites vulcanized using cylindrically shaped mold of $8 \mathrm{~mm}$ of height and $16 \mathrm{~mm}$ of diameter were thermally treated by PWP Prod-Ryn laboratory furnace (Poland), being subjected to heating form room temperature to $1050{ }^{\circ} \mathrm{C}$ (heating rate of $\sim 5^{\circ} \mathrm{C} / \mathrm{min}$ ) and afterwards conditioned at the maximum temperature for $30 \mathrm{~min}$. Subsequently, ceramified samples were left to cool down to room temperature. Compression strength of ceramified composites was determined by means of Zwick-Roell Z 2.5 instrument (Germany). Compression strength of the materials was calculated as an average value of 5-7 determinations.

\section{Results and discussion}

\section{Kinetics of vulcanization}

Vulcanization kinetics of the composite mixes measured directly after preparation and after a week of conditioning is presented in Figs. 2 and 3, respectively. Total torque increase values are gathered in Table 3.

The results obtained demonstrate that addition of CbMix can significantly affect the kinetics of the mix vulcanization or even prevent it, especially after long time of storage. On the whole, the vulcanization kinetics of the mixes occurred very fast, what is important from the point of view of the vulcanization during high-speed extrusion technology used commonly in cable industry. Even CAO mix before storage exhibits a satisfactory vulcanization behavior. Table 3 demonstrates the increase to torque after a week of the composite mixes conditioning. For the majority of the mixes a slight increase in torque value can be observed. The only sample filled with CbMix shows dramatic drop of torque value increase $(\Delta M)$ after a time period of conditioning in storage conditions. The negative effect of high

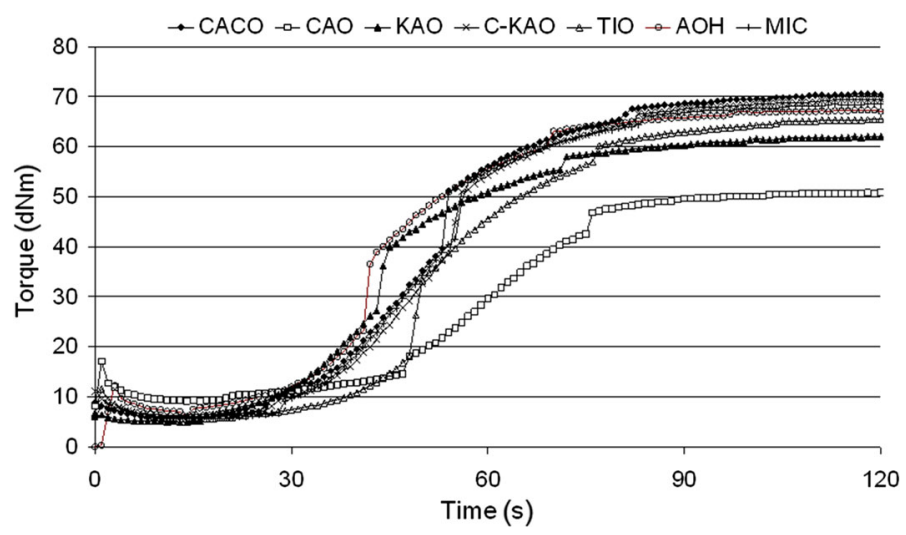

Fig. 2 Vulcanization kinetics of the composite mixes measured directly after preparation 


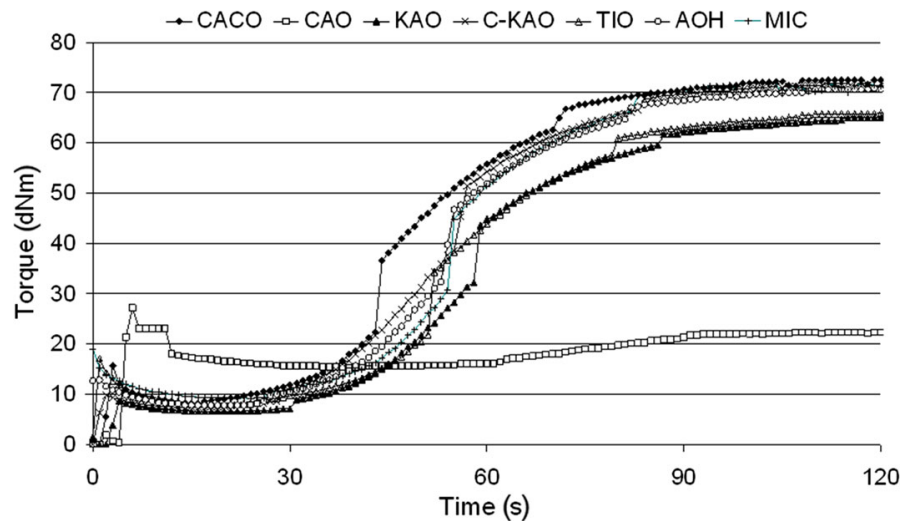

Fig. 3 Vulcanization kinetics of the composite mixes measured after 7 days of conditioning

Table 3 Torque increase $(\Delta M)$ measured for samples directly after preparation and after 7 days of storage

\begin{tabular}{|c|c|c|c|c|c|c|c|}
\hline \multirow[t]{2}{*}{ Parameter $(\mathrm{dNm})$} & \multicolumn{7}{|c|}{ Sample description } \\
\hline & C-KAO & MIC & TIO & $\mathrm{CAO}$ & KAO & $\mathrm{AOH}$ & CACO \\
\hline$\Delta M 0$ days & 63 & 62 & 59 & 41 & 56 & 61 & 64 \\
\hline$\Delta M 7$ days & 65 & 66 & 59 & 7 & 59 & 64 & 66 \\
\hline
\end{tabular}

amount of CbMix on 2,4-dichlorobenzoyl peroxide cross-linking efficiency of silicone rubber has been already observed previously in the relevant literature [42] and is probably caused by alkaline character of $\mathrm{Ca}(\mathrm{OH})_{2}$, which is a predominant constituent of the filler. Finally, the peroxide adsorption on the surface of the CbMix particles may contribute to its deactivation.

\section{Mechanical properties}

For the mechanical properties of the composites vulcanized directly after preparation, see Table 4.

Generally almost all samples exhibit tensile strength value over $5 \mathrm{MPa}$ and as such they prove suitable for cable industry, where the value of $5 \mathrm{MPa}$ is often considered the lowest limit for ceramifiable silicone composites utilization. The only sample filled with CbMix (4.3 MPa) does not meet this requirement, which is probably caused by its lower cross-link density in comparison to other composites. The strongest samples were filled with kaolin (5.8 MPa) and calcined kaolin (6.0 MPa). Tensile strength of the composites is closely connected with polar part of the additional filler surface free energy and increases with the decrease of polar part value, (Table 1). This is probably due to the non-polar character of the silicone matrix, which interacts with surface of filler exhibiting polar properties very poorly. 
Table 4 Mechanical properties of the vulcanizates studied. Stress at 100\% (SE100), 200\% (SE200) and $300 \%$ (SE300) of elongation, tensile strength (TS), and elongation at break (Eb)

\begin{tabular}{lllllllll}
\hline & C-KAO & MIC & TIO & CAO & KAO & AOH & CACO & Ref $^{\text {a }}$ \\
\hline SE100 (MPa) & 2.5 & 2.1 & 1.7 & 1.7 & 2.2 & 1.9 & 2.0 & 1.3 \\
SE200 (MPa) & 4.3 & 3.4 & 3.2 & 2.7 & 3.5 & 3.2 & 3.5 & 3.1 \\
SE300 (MPa) & - & 5.3 & 4.9 & 3.8 & 5.2 & 5.1 & - & 5.5 \\
TS (MPa) & 6.0 & 5.3 & 5.2 & 4.3 & 5.8 & 5.4 & 5.2 & 10.4 \\
Eb $(\%)$ & 295 & 300 & 305 & 330 & 330 & 310 & 290 & 490 \\
\hline
\end{tabular}

${ }^{a}$ Mechanical properties of the reference sample filled only with fumed silica and cured with peroxide

Simultaneously, the average size of the functional fillers particles seems not to influence this parameter visibly. This is probably due to their relatively large size facilitating semi- or non-reinforcing properties. In such conditions, the compatibility between the filler surface and silicone rubber plays a much more significant role than the filler capability to form secondary-reinforcing structure inside the elastomer matrix. Elongations at break of the composites are very similar for all samples. However, the composites filled with kaolin $(330 \%)$ and calcium oxide $(330 \%)$ exhibit a slightly higher elasticity than others, whereas the composite containing calcium carbonate exhibits the lowest elasticity (290\%). Generally, the mechanical properties of the composites depend mostly on the presence of fluxing agent, whose large particles weaken the internal semi-continuous structure of the silicone rubber matrix (Fig. 4). Nevertheless, the presence of an additional mineral filler modifies stress-strain characteristic of the composites noticeably. A much more accurate characteristic of the composites micromorphology along with EDS elemental analysis is available as a supplementary material for this article (Figs. 1S-7S). Except for the reference sample (Ref.) composed only of silicone rubber reinforced with fumed silica and cured with the peroxide, all of the composites exhibit lower values of tensile strength along with elongation at break. This phenomenon was expected due to the non-reinforcing character of the fluxing agent of large particles and semi-reinforcing or non-reinforcing properties of additional, functional fillers. Nevertheless, mechanical properties of the composites emerge as satisfactory from the point of view of their potential application in the cable industry.

\section{Flammability and smoke intensity}

Flammability of all the composites is comparable to other flame-retarded siliconebased materials presented in the literature (Table 5) [21]. It is not the low flammability that is the most important feature of the composites, but their ability to form a protective ceramic structure. However, high flame retardancy of the composites is also beneficial from the point of view of ceramification process, which seems to be much more effective when the composites are not exposed to rapid temperature growth. High flame retardancy of composites suppresses growth 

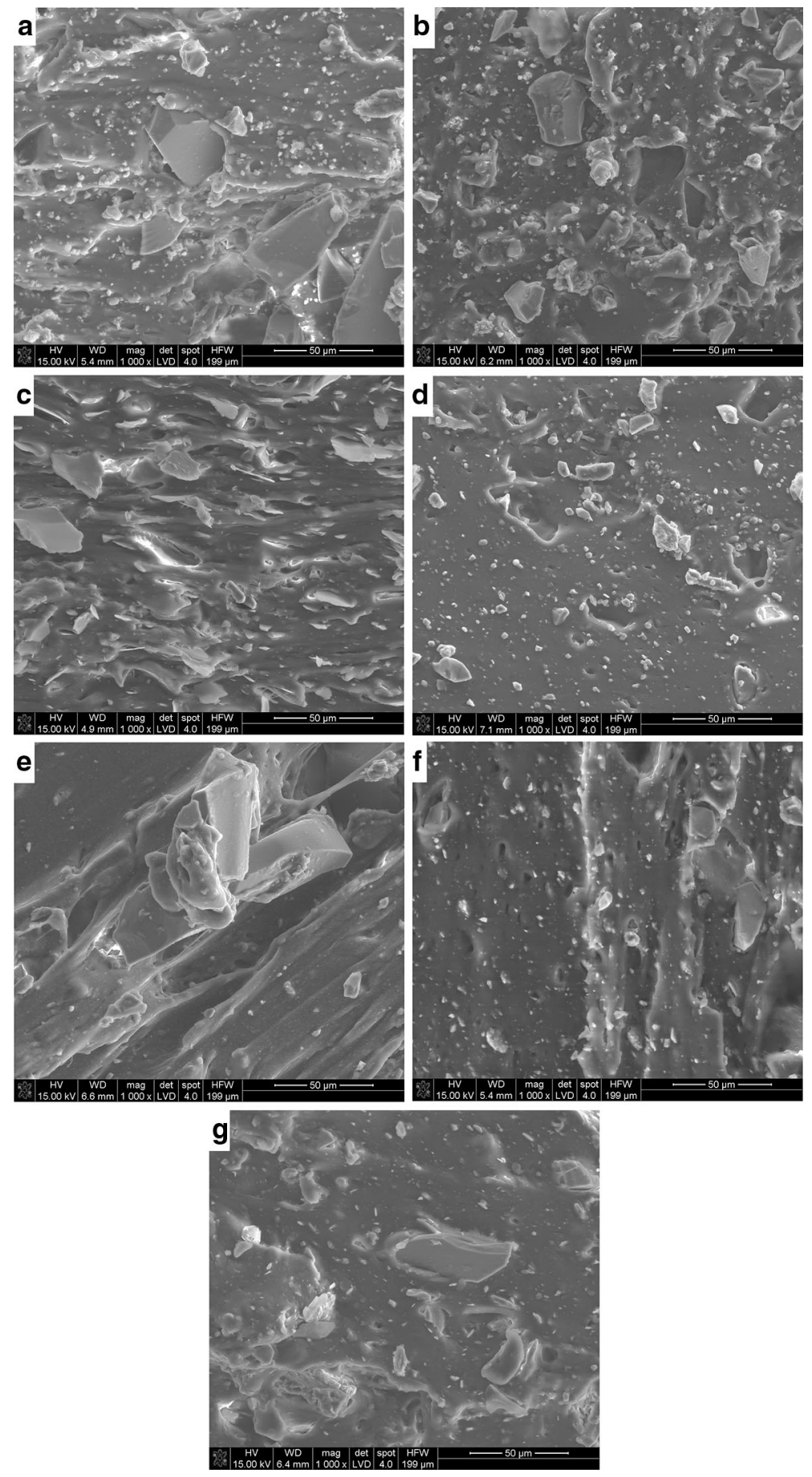
Fig. 4 SEM photographs of a CAO, b CACO, $\mathbf{c} \mathrm{MIC}$, d AOH, e TIO, f C-KAO, g KAO samples crosssections before ceramification, taken under magnification of $1000 \times$

of fire and temperature, facilitating favorable-mild conditions for ceramification [15].

The addition of $\mathrm{CbMix}$ or $\mathrm{Al}(\mathrm{OH})_{3}$ facilitates the highest increase of the flame retardancy of a ceramifiable silicone composite (Fig. 5; Table 5). Both fillers release considerable amount of water during the heat increase (Fig. 6a) which is accompanied by significant endothermal effect (Fig. 6b). Furthermore, the temperature of water release from these fillers is visibly lower than temperature of $\mathrm{CO}_{2}$ release from $\mathrm{CaCO}_{3}$ or water from kaolin. It is highly probable that those three factors combined exert a profound impact on flame retardancy of the composites, especially when KAO composite exhibits one of the worst flame retardant properties from all the composites studied, despite the fact that the kaolin contains over $10 \%$ of bonded water. The endothermal effect of water release from kaolin is very low and the temperature range of the release relatively high (above the temperature of thermal decomposition of the silicone rubber matrix). As a result, the addition of kaolin cannot decrease the flammability of the composite effectively. A similar effect is observed for the CACO composite filled with $\mathrm{CaCO}_{3}$, which releases $\mathrm{CO}_{2}$ in a too high temperature range to suppress flammability of the composite significantly, despite the considerable endothermal effect accompanying the release (Fig. 6b).

Table 5 Flammability parameters: oxygen index (OI), smoke intensity (SI), time to ignition $\left(t_{\mathrm{i}}\right)$, time to flameout $\left(t_{\mathrm{o}}\right)$, total heat release (THR), mass loss $\left(\mathrm{m}_{1}\right)$, heat release rate peak $\left(\mathrm{HRR}_{\mathrm{p}}\right)$ and its mean value $\left(\mathrm{HRR}_{\mathrm{m}}\right)$, time to heat release rate peak $\left(t_{\mathrm{HRRp}}\right)$, effective heat of combustion peak $\left(\mathrm{EHC}_{\mathrm{p}}\right)$ and its mean value $\left(\mathrm{EHC}_{\mathrm{m}}\right)$, time to effective heat of combustion peak $\left(t_{\mathrm{EHCp}}\right)$, mass loss rate peak $\left(\mathrm{MLR}_{\mathrm{p}}\right)$ and its mean value $\left(\mathrm{MLR}_{\mathrm{m}}\right)$ and time to mass loss rate peak $\left(t_{\mathrm{MLRp}}\right)$

\begin{tabular}{llllllll}
\hline & C-KAO & MIC & TIO & CAO & KAO & AOH & CACO \\
\hline OI $(\%)$ & 26.1 & 28.1 & 27.1 & 31.4 & 25.0 & 28.1 & 28.2 \\
SI $(1 \times s)$ & 19,680 & 20,280 & 20,640 & 19,176 & 14,448 & 19,104 & 20,232 \\
$t_{\mathrm{i}}(\mathrm{s})$ & 98 & 109 & 110 & 86 & 144 & 83 & 111 \\
$t_{\mathrm{o}}(\mathrm{s})$ & 385 & 555 & 556 & 569 & 563 & 503 & 372 \\
$\mathrm{THR}\left(\mathrm{MJ} / \mathrm{m}^{2}\right)$ & 14.4 & 13.4 & 13.8 & 9.3 & 17.6 & 11.0 & 12.7 \\
$\mathrm{~m}_{1}(\%)$ & 23.5 & 23.2 & 23.8 & 28.9 & 29.7 & 29.7 & 17.5 \\
$\mathrm{HRR}_{\mathrm{p}}\left(\mathrm{kW} / \mathrm{m}^{2}\right)$ & 88.6 & 72.5 & 79.2 & 60.0 & 86.1 & 57.6 & 77.8 \\
$\operatorname{HRR}_{\mathrm{m}}\left(\mathrm{kW} / \mathrm{m}^{2}\right)$ & 48.6 & 27.8 & 28.0 & 11.8 & 41.1 & 23.3 & 48.0 \\
$\mathrm{t}_{\mathrm{HRRp}}(\mathrm{s})$ & 185 & 225 & 215 & 185 & 270 & 235 & 210 \\
$\operatorname{EHC}_{\mathrm{p}}(\mathrm{MJ} / \mathrm{kg})$ & 73.7 & 63.4 & 54.0 & 43.8 & 72.8 & 63.7 & 68.6 \\
$\mathrm{EHC}_{\mathrm{m}}(\mathrm{MJ} / \mathrm{kg})$ & 15.7 & 18.8 & 15.6 & 6.5 & 21.7 & 11.5 & 26.2 \\
$t_{\mathrm{EHCp}}(\mathrm{s})$ & 270 & 275 & 265 & 275 & 495 & 320 & 260 \\
$\operatorname{MLR}_{\mathrm{p}}(\mathrm{g} / \mathrm{s})$ & 0.283 & 0.058 & 0.178 & 0.062 & 0.051 & 0.060 & 0.053 \\
$\operatorname{MLR}_{\mathrm{m}}(\mathrm{g} / \mathrm{s})$ & 0.026 & 0.013 & 0.016 & 0.016 & 0.017 & 0.018 & 0.016 \\
$t_{\mathrm{MLRp}_{\mathrm{p}}}(\mathrm{s})$ & 105 & 110 & 120 & 125 & 235 & 85 & 140 \\
\hline
\end{tabular}




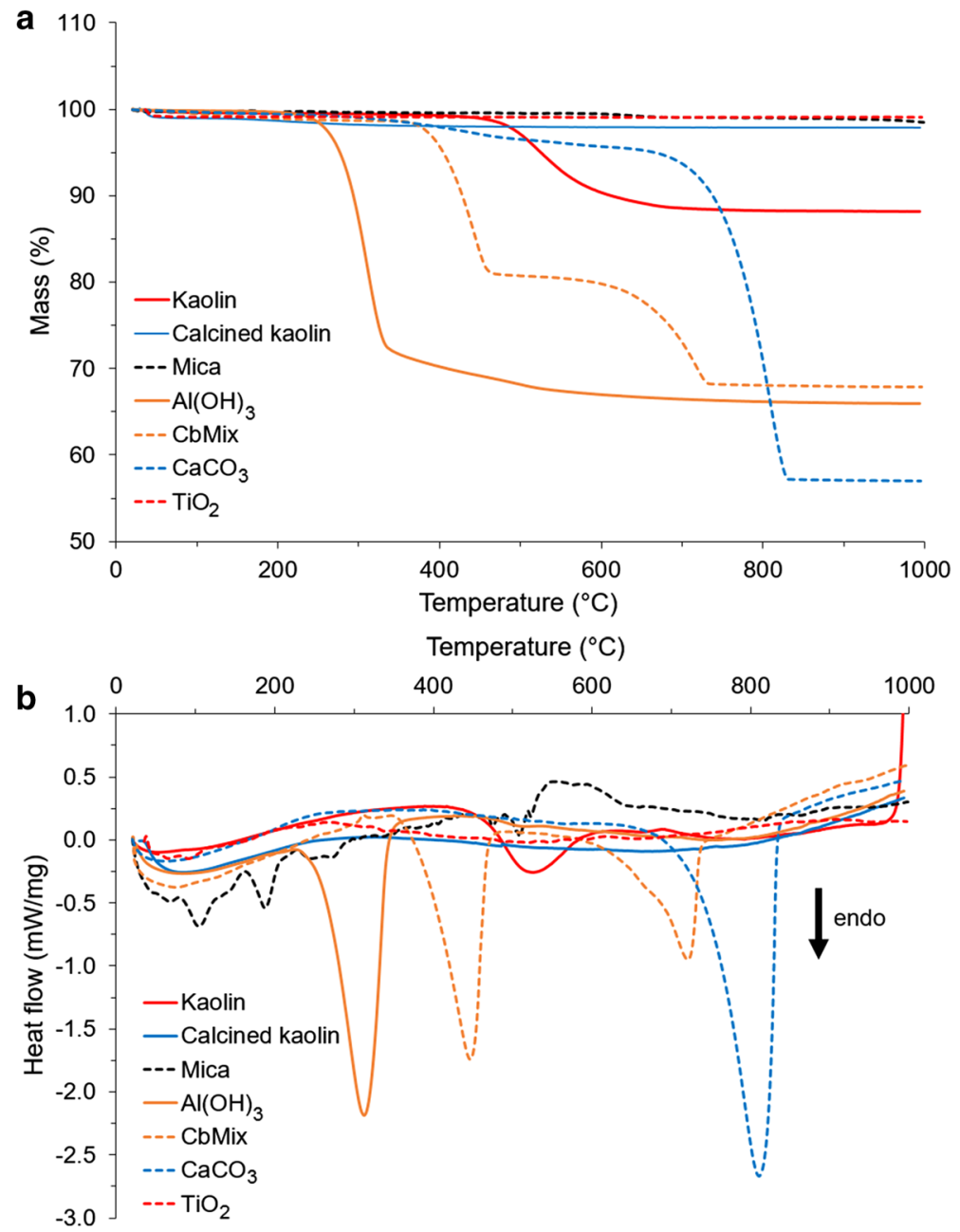

Fig. 5 Thermogravimetric (a) and differential scanning calorimetry (b) analysis of the mineral fillers

Similarly, in terms of smoke emission intensity, the composite filled with kaolin exhibits the worst properties. Its smoke intensity value places the composite in D2 group with accordance to PN-91/K-02501 standard ( $\leq 18,000$ 1xs). The remaining composites exhibit satisfying properties according to smoke emission density criteria, which place them in D1 group. The lowest smoke emission was observed for TIO sample.

\section{Mechanical properties of ceramified residue}

The composites subjected to ceramification were subsequently compared according to their compression strength (Fig. 7). The values of compression force required to crushing of the composite samples are presented in Table 6 as well as the changes of 

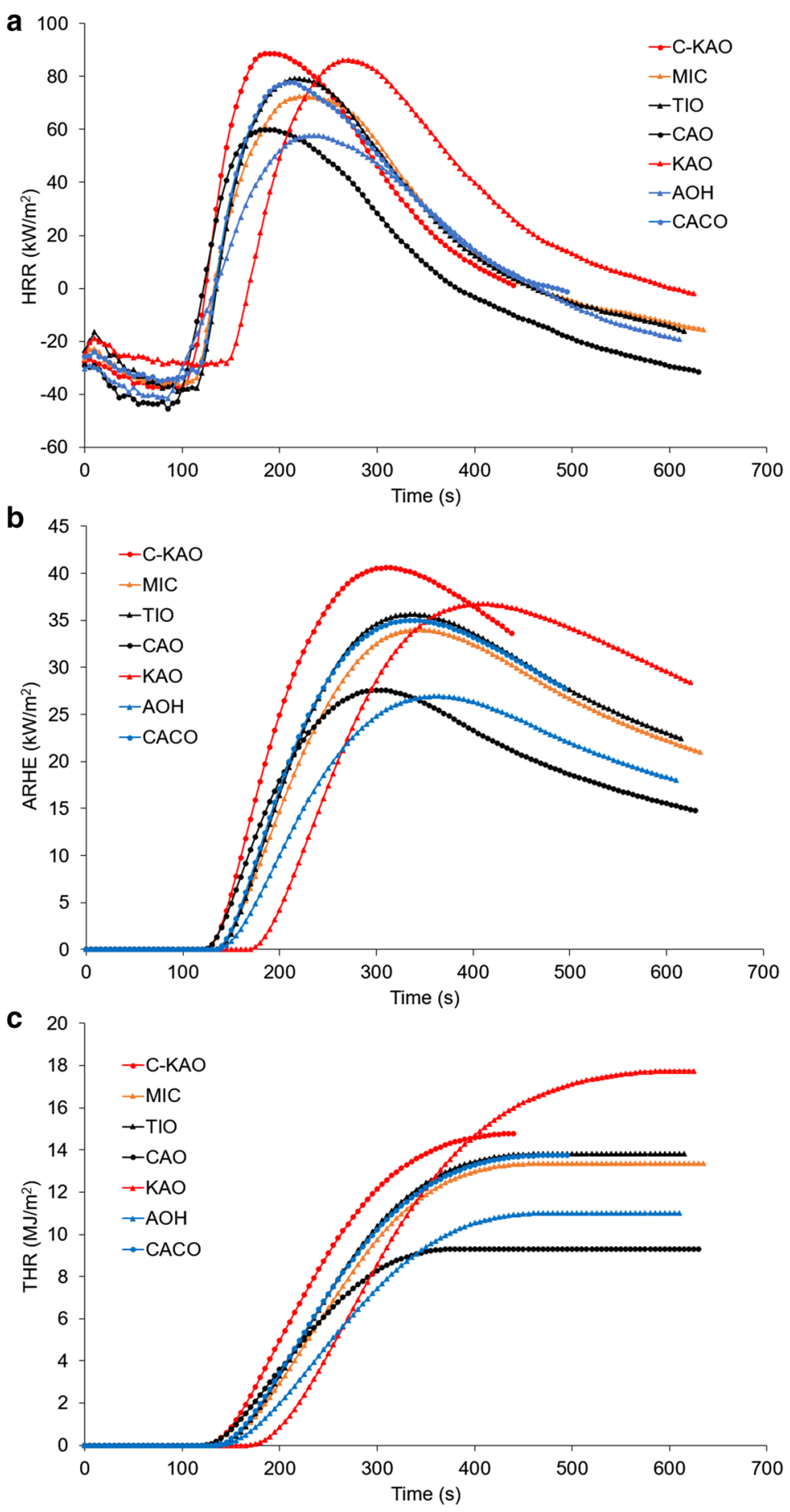
Fig. 6 Flammability parameters of the composites: a heat release rate (HRR), b averaged heat release rate (ARHE) and $\mathbf{c}$ total heat released (THR)

height and diameter of the cylindrically shaped samples. The composites containing calcium-based mineral fillers (CAO, CACO) created the strongest ceramic structure after ceramification. Force required to destroy them was over two times higher than the force required to destroy the third of the strongest samples (TIO). This is most probably the result of formation of different reinforcing polymorphs of $\mathrm{CaSiO}_{3}$ produced during the thermal treatment of the composites accompanied by highly homogenous micromorphology of these composites. This effect is much thoroughly described in "Micromorphology of ceremified residue". The weakest ceramic phases were obtained for MIC and $\mathrm{AOH}$ samples filled with phlogopite mica (MIC) and aluminum hydroxide $(\mathrm{AOH})$, respectively. All samples exhibit an increase in their height after ceramification, most probably due to the direction of escaping volatiles, whereas the diameter of the samples generally decreases, with an exception of the sample filled with aluminum hydroxide whose diameter is increased by over $2 \mathrm{~mm}$.

\section{Micromorphology of ceramified residue}

\section{SEM analysis}

Scanning electron microscope photographs of the cross section of ceramified samples, taken with the magnification of $2000 \times$, were examined to explain significant differences in the mechanical strength of the samples filled with a different type of mineral powders (Fig. 8). SEM photographs indicate that the samples facilitating the highest mechanical strength (CAO and CACO) create the most regular porous structure after ceramification (Figs. 8a, b, respectively). The adhesion between the wetting glassy phase and mineral particles dispersed in it is substantial, what enables creation of homogenous microstructure, whereas, the weakest samples (MIC and $\mathrm{AOH}$ ) create dissimilar structures during heat treatment (Figs. 8c, d, respectively). Micromorphology of the composite filled with mica consists of relatively large pores and continuous cell wall phase formed on mica flakes backbone, stuck together with fluxing agent and amorphous silica created during thermooxidative degradation of silicone matrix. The micromorphology of the composite is probably responsible for poor mechanical endurance. The $\mathrm{AOH}$

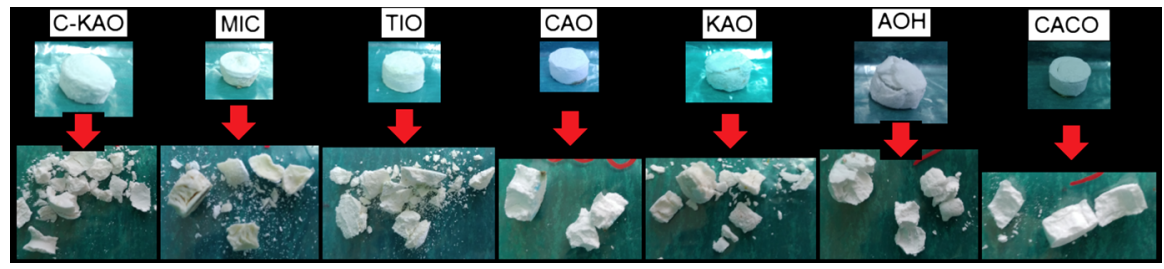

Fig. 7 Photographs of the composites samples after ceramification, before and after the mechanical tests 


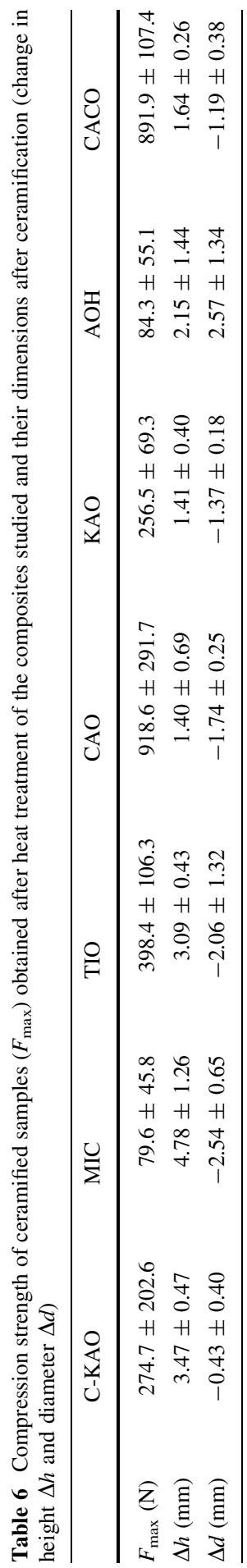



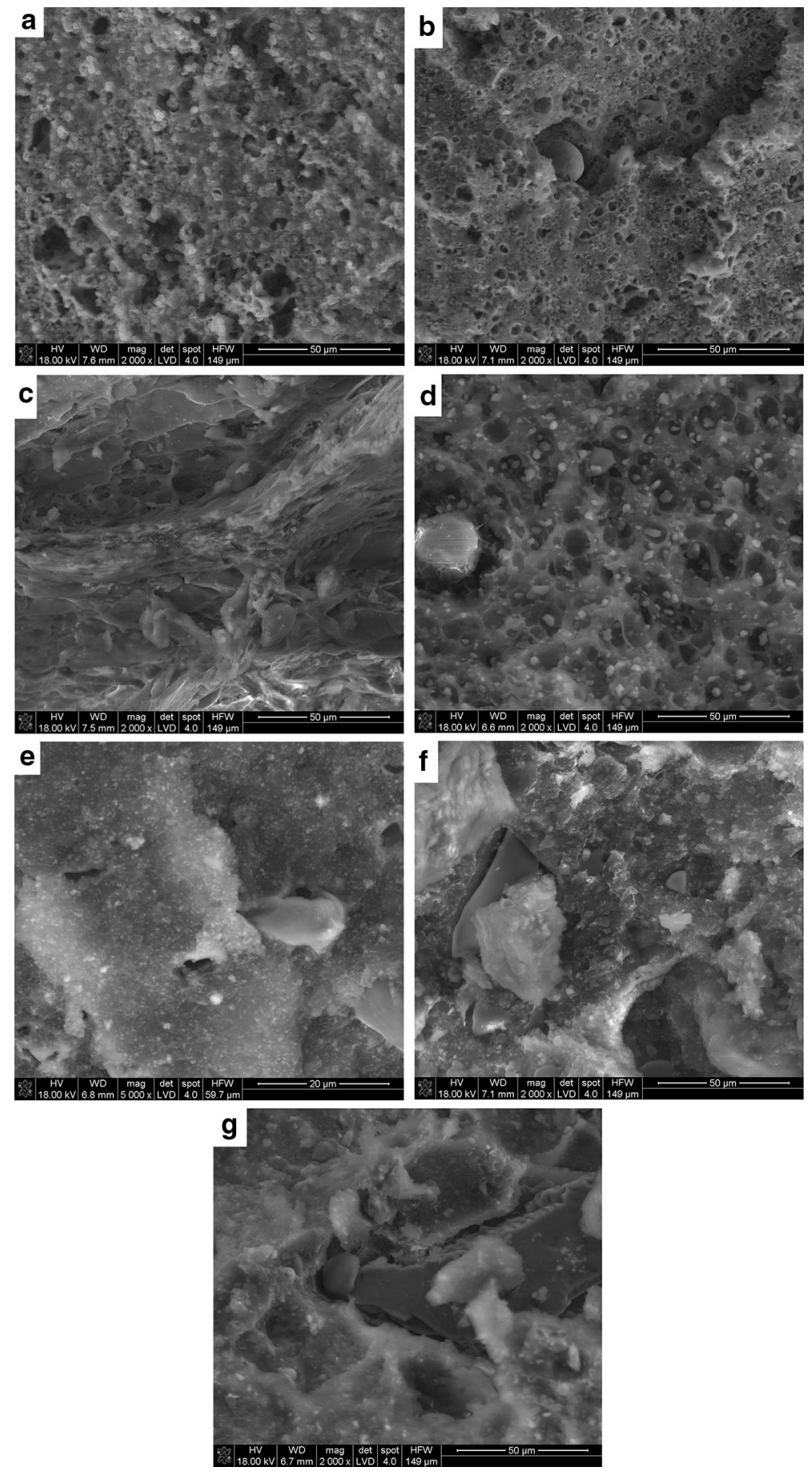
Fig. 8 SEM photographs of a CAO, b CACO, c MIC, d AOH, e TIO, f C-KAO, g KAO samples crosssections after ceramification, taken under magnification of $2000 \times$

composite following heat treatment exhibits the worst microstructure, since the adhesion between $\mathrm{Al}_{2} \mathrm{O}_{3}$ particles created after dehydroxylation of $\mathrm{Al}(\mathrm{OH})_{3}$ and continuous, a glassy phase formed from a fluxing agent and amorphous silica is very weak. Similarly to the MIC sample, the low mechanical properties of AOH composite stem from the poor homogeneity of its micromorphology created after heat treatment. The rest of the samples is characterized by an average value of strength under compression even in case of TIO whose micromorphology appears similar to CAO and CACO composites (Fig. 8e).

\section{Diffractometry}

The results of XRD analysis of ceramified materials CAO and CACO are collected in Figs. 9 and 10, respectively. Only the most intensive peaks of identified phases were indicated in the Figures. Non-described ones corresponded to identified phases. The results of the performed analyses of CAO and CACO samples indicate that the type and amount of the created wollastonite differs depending on the source of $\mathrm{Ca}$. Both detected parawollastonite and pseudowollastonite phases were the same type of mineral wollastonite with the same chemical formula $\left(\mathrm{CaSiO}_{3}\right)$ but different crystallographic structure. Their presence was the result of the reaction between reinforcing fumed silica or silica created during thermooxidative degradation of silicone rubber and calcium oxide created during decarbonylation of $\mathrm{CaCO}_{3}$ or dihydroxylation of $\mathrm{Ca}(\mathrm{OH})_{2}$. This phenomenon was previously described by Gardelle et al. who investigated the resistance of silicone-based coatings to cellulosic fire [43]. The creation of pseudowollastonite and parawollastonite during heat treatment of the composites can play a significant role in the formation of a

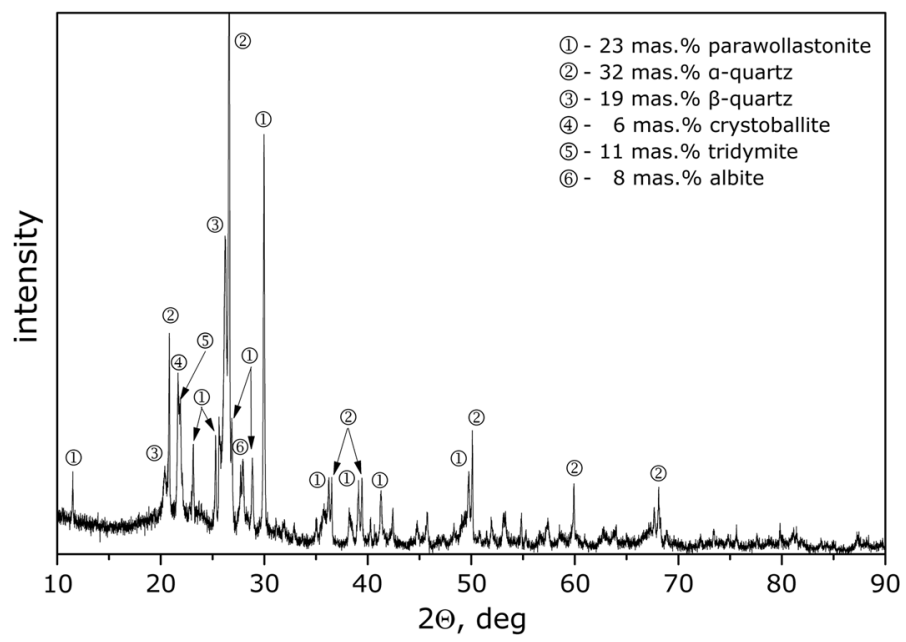

Fig. 9 X-ray diffractogram of mineral char obtained from CAO sample heat treatment 


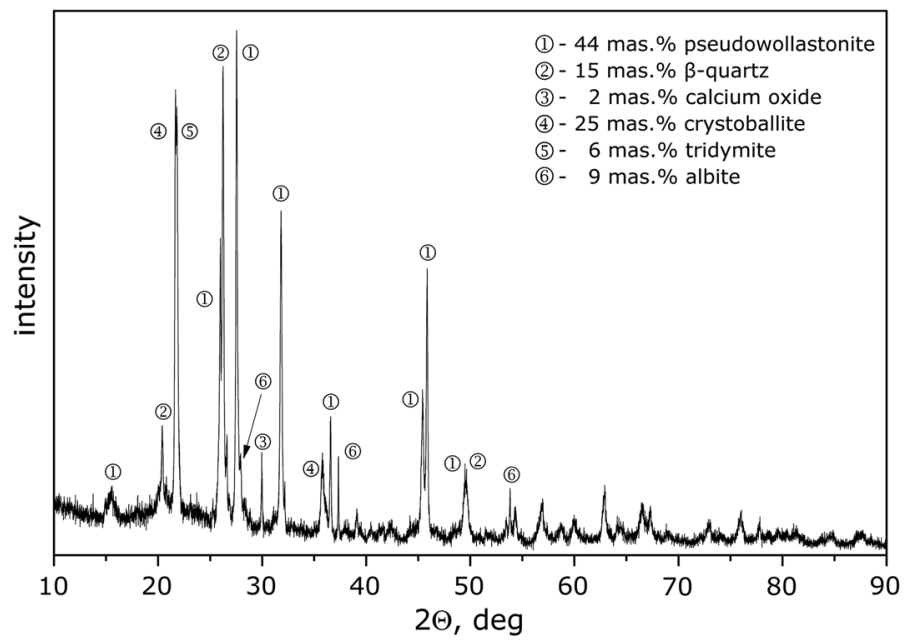

Fig. 10 X-ray diffractogram of mineral char obtained from CACO sample heat treatment

mechanically robust mineral structure. The significantly higher amount of calcium silicate was recorded in CACO sample.

The presence of different polymorphs of silicon dioxide could be explained with chemical complexity and non-homogeneity of the system. Some alkali cations dispersed in composite could have stabilized high temperature silica phases, as well as non-controlled cooling conditions after ceramification.

\section{Summary and conclusion}

It emerges that the type of mineral filler may affect peroxide curing process of silicone rubber-based ceramifiable composites. It is most visible in the addition of CbMix which results in a significant decrease of vulcanization effectiveness of silicone rubber. Presumably it may be due to the alkaline character of the $\mathrm{CaO}$ and $\mathrm{Ca}(\mathrm{OH})_{2}$ or adsorption of the peroxide on the surface of a filler. In this study, the sample containing such a filler was practically unable to cure after 7 days of conditioning in storage conditions.

The type of mineral refractory filler also affects mechanical properties of ceramifiable composites. Irrespective of cross-linking density different kinds of mineral powders can make a composite stiffer or more elastic (elongation at break $\mathrm{Eb}=290-330 \%$, stress at $100 \%$ of elongation SE100 $=1.7-2.5 \mathrm{MPa}$, stress at $200 \%$ of elongation SE200 $=3.2-4.3 \mathrm{MPa}$, stress at $300 \%$ of elongation SE300 = 5.1-6.3 MPa, tensile strength TS = 5.2-6.0 MPa). The best reinforcing effect is exhibited by calcined kaolin and kaolin most probably due to the low value of polar part of their surface free energy, which favors interactions with a non-polar silicone rubber matrix. Size distribution of the additional mineral fillers particles seems to play a minor role in the mechanical properties of the composites in comparison to their surface free energy. 
Nevertheless, the composites displaying the best mechanical properties (KAO, C-KAO) do not facilitate similar good fire retardancy, especially the composite containing kaolin exhibits the poorest properties in terms of smoke intensity (D2medium intensity of smoking) and flammability. The best fire resistance is exhibited by the composites filled with aluminum hydroxide or CbMix, which disturbs vulcanization process. All other composites exhibit low intensity of smoking (D1 group) and low flammability, what predestines them for flame resistant applications.

The strongest ceramic phases created during ceramification were obtained from composites containing calcium-based refractory fillers (CAO, CACO) as the result of creation calcium silicates (wollastonite, pseudowollastonite and parawollastonite) accompanied by highly homogenous micromorphology of the formed ceramic structure. Ceramic structures of the lowest mechanical strength were produced after ceramification of samples containing phlogopite mica (MIC) and aluminum hydroxide $(\mathrm{AOH})$. This can be explained by poor homogeneity of their micromorphology. Aluminum oxide created during thermal dehydroxilation of $\mathrm{Al}(\mathrm{OH})_{3}$ shows low adhesion to liquid glassy phase, what results in a mechanically weak ceramic structure. The composite containing mica creates a non-homogeneous ceramic microstructure that consists of large pores and what in turn negatively affects their mechanical properties.

Acknowledgements Sincere thanks to Martyna Kościukiewicz for providing language help: https://pl. linkedin.com/pub/martyna-kościukiewicz/108/456/76b/pl. This work was supported by the European Union Integrity Fund, project "Composition and a way of production of silicone rubber based composites", UDA-POIG.01.03.02-00-025/12-00. This research was supported by the Young Scientists' Fund at the Faculty of Chemistry, Lodz University of Technology, Grant No: W-3D/FMN/32G/2016. The authors are deeply indebted to Prof. Mirosław M. Bućko (AGH - University of Science and Technology, Krakow) for the help provided in the interpretation of the XRD results.

Open Access This article is distributed under the terms of the Creative Commons Attribution 4.0 International License (http://creativecommons.org/licenses/by/4.0/), which permits unrestricted use, distribution, and reproduction in any medium, provided you give appropriate credit to the original author(s) and the source, provide a link to the Creative Commons license, and indicate if changes were made.

\section{References}

1. Stryczek ZB, Roberts DG (2014) New low smoke zero halogen tray cable jacket materials designed for balance of cost, performance and enhanced fire resistance. Proc 63rd Int Conf on International Wire and Cable Symposium, Rhode Island, USA, pp 713-717

2. Liao YJ, Liao GX, Lo SM, Ma J, Liu SB (2014) A study on people's attitude to the use of elevators for fire escape. Fire Technol 50:363-378

3. Liu J, Wu S, Zou M, Zheng X, Cai Z (2012) Surface modification of silica and its compounding with polydimethylsiloxane matrix: interaction of modified silica filler with PDMS. Iran Polym J 21:583-589

4. Ghane M, Ramazanpour M, Sheikhzadeh M (2012) Thermal retardant properties of textiles impregnated with ceramic powder. Mater Technol 27:315-319

5. Hamdani S, Longuet C, Lopez-Cuesta J-M, Ganachaud F (2010) Calcium and aluminium-based fillers as flame-retardant additives in silicone matrices. I. Blend preparation and thermal properties. Polym Degrad Stabil 95:1911-1919 
6. Hamdani-Devarennes S, Pommier A, Longuet C, Lopez-Cuesta J-M, Ganachaud F (2011) Calcium and aluminium-based fillers as flame-retardant additives in silicone matrices. II. Analyses on composite residues from an industrial-based pyrolysis test. Polym Degrad Stabil 96:1562-1572

7. Hamdani-Devarennes S, Longuet C, Sonnier R, Ganachaud F, Lopez-Cuesta J-M (2013) Calcium and aluminium-based fillers as flame-retardant additives in silicone matrices. III. Investigations on fire reaction. Polym Degrad Stabil 98:2021-2032

8. Hamdani S, Longuet C, Perrin D, Lopez-Cuesta J-M, Ganachaud F (2009) Flame retardancy of silicone-based materials. Polym Degrad Stabil 94:465-495

9. Mansouri J, Wood CA, Roberts K, Cheng YB, Burford RP (2007) Investigation of the ceramifying process of modified silicone-silicate compositions. J Mater Sci 42:6046-6055

10. Mansouri J, Burford RP, Cheng YB, Hanu L (2005) Formation of strong ceramified ash from silicone-based composites. J Mater Sci 40:5741-5749

11. Mansouri J, Burford RP, Cheng YB (2006) Pyrolysis behaviour of silicone-based ceramifying composites. Mat Sci Eng A 425:7-14

12. Hanu LG, Simon GP, Mansouri J, Burford RP, Cheng YB (2004) Development of polymer-ceramic composites for improved fire resistance. J Mater Process Tech 153-154:401-407

13. Hanu LG, Simon GP, Cheng YB (2006) Thermal stability and flammability of silicone polymer composites. Polym Degrad Stabil 91:1373-1379

14. Hanu LG, Simon GP, Cheng YB (2005) Preferential orientation of muscovite in ceramifiable silicone composites. Mat Sci Eng A 398:180-187

15. Wang J, Ji C, Yan Y, Zhao D, Shi L (2015) Mechanical and ceramifiable properties of silicone rubber filled with different inorganic fillers. Polym Degrad Stabil 121:149-156

16. Xiong Y, Shen Q, Chen F, Luo G, Yu K, Zhang L (2012) High strength retention and dimensional stability of silicone/alumina composite panel under fire. Fire Mater 36:254-263

17. Pędzich Z, Anyszka R, Bieliński DM, Ziąbka M, Lach R, Zarzecka-Napierała M (2013) SiliconBasing Ceramizable Composites Containing Long Fibers. J Mat Sci Chem Eng 1:43-48

18. Imiela M, Anyszka R, Bieliński DM, Pędzich Z, Zarzecka-Napierała M, Szumera M (2016) Effect of carbon fibers on thermal properties and mechanical strength of ceramizable composites based on silicone rubber. J Therm Anal Calorim 124:197-203

19. Anyszka R, Bieliński DM, Pędzich Z, Szumera M (2015) Influence of surface-modified montmorillonites on properties of silicone rubber-based ceramizable composites. J Therm Anal Calorim 119:111-121

20. Rybiński P, Żukowski W, Bradło D (2015) Influence of cenosphere particles on thermal properties composites of silicon rubber. J Therm Anal Calorim 122:1307-1318

21. Rybiński P, Żukowski W, Bradło D (2016) Effect of cenospheric fillers on the flammability and fire hazard of silicone rubber composites. J Therm Anal Calorim 125:1373-1386

22. Anyszka R, Bieliński DM, Pędzich Z, Zarzecka-Napierała M, Ziąbka M, Kowalczyk M (2014) Effect of mineral fillers on properties of silicone rubber-based ceramizable composites. Part 1. Kinetics of vulcanization and mechanical properties of composites. Przem Chem 93:1291-1295

23. Anyszka R, Bieliński DM, Pędzich Z, Zarzecka-Napierała M, Ziąbka M, Kowalczyk M (2014) Effect of mineral fillers on properties of silicone rubber-based ceramizable composites. Part 2. Characteristics of a mineral phase produced by ceramization of composites. Przem Chem 93:1684-1689

24. Hu LH, Zhang Y, Yoshioka K, Izuma H, Fujita O (2015) Flame spread over electric wire with high thermal conductivity metal core at different inclinations. P Combust Inst 35:2607-2614

25. Pająk A, Janowska G, Czajkowski W, Kucharska-Jastrząbek A (2010) Effect of the phthalocyanine pigments on the properties of butadiene rubber. Przem Chem 89:1189-1192

26. Janowska G, Kucharska-Jastrząbek A, Rzymski WM, Pająk A (2012) Thermal properties nad combustibility of cross-linked XNBR/CSM blends. J Therm Anal Calorim 109:1481-1486

27. Kmiotek M, Bieliński DM, Anyszka R, Kleczewska J, Siciński M (2013) Flammability and thermal stability of vulcanized rubber mixes. Przem Chem 92:1741-1746

28. Alvares N, Hasegawa H, Staggs K (2016) Ignition, heat release rate and suppression of elastomeric materials. Fire Technol 52:1575-1593

29. Rybiński P, Janowska G, Kucharska-Jastrząbek A, Pająk A, Wójcik I, Wesołek D, Bujnowicz K (2012) Flammability of vulcanizates of diene rubbers. J Therm Anal Calorim 107:1219-1224

30. Rybiński P, Janowska G, Jóźwiak M, Pająk A (2012) Thermal stability and flammability of butadiene-styrene rubber nanocomposites. J Therm Anal Calorim 109:561-571 
31. Rybiński P, Janowska G (2014) Effect of the spatial network structure and cross-link density of diene rubbers on their thermal stability and fire hazard. J Therm Anal Calorim 117:377-386

32. Liu L, Zhuo J, Chen X, Jiao C, Li S, Gu Y (2015) Influence of ferric hydroxide on smoke suppression properties and combustion behavior of intumescent flame retardant silicone rubber composites. J Therm Anal Calorim 119:487-497

33. Zhang J, Bai M, Wang Y, Xiao F (2012) Featured structures of fire residue of high-impact polystyrene/organically modified montmorillonite nanocomposites during burning. Fire Mater 36:661-670

34. Wang T, Shao H, Zhang Q (2010) Ceramifying fire-resistant polyethylene composites. Adv Compos Lett 19:175-179

35. Shanks RA, Al-Hassany Z, Genovese A (2010) Fire-retardant and fire-barrier poly (vinyl acetate) composites for sealant application. Express Polym Lett 4:79-93

36. Shanks RA, Wong S, Preston CML (2010) Ceramifying fire-retardant and fire-barrier unsaturated polyester composites. Adv Mat Res 123-125:23-26

37. Anyszka R, Bieliński DM, Pędzich Z, Rybiński P, Imiela M, Siciński M, Zarzecka-Napierała M, Gozdek T, Rutkowski P (2016) Thermal stability and flammability of styrene-butadiene rubber-based (SBR) ceramifiable composites. Materials 9:604

38. Di H-W, Deng C, Li R-M, Dong L-P, Wang Y-Z (2015) A novel EVA composite with simultaneous flame retardation and ceramifiable capacity. RSC Adv 5:51248-51257

39. Ferg EE, Hlangothi SP, Bambalaza S (2017) An experimental design approach in formulating a ceramifiable EVA/PDMS composite coating for electric cable insulation. Polym Composite 38:371-380

40. Morgan AB, Chu LL, Harris JD (2005) A flammability performance comparison between synthetic and natural clays in polystyrene nanocomposites. Fire Mater 29:213-229

41. Delebecq E, Hamdani-Devarennes S, Raeke J, Lopez Cuesta J-M, Ganachaud F (2011) High residue contents indebted by platinum and silica synergistic action during the pyrolysis of silicone formulations. ACS Appl Mater Interfaces 3:869-880

42. Anyszka R, Bieliński DM, Kowalczyk M (2013) Influence of dispersed phase selection on ceramizable silicone composites cross-linking. Elastomers 17:16-20

43. Gardelle B, Duquesne S, Vandereecken P, Bourbigot S (2014) Resistance to fire of silicone-based coatings. Fire protection of steel against cellulosic fire. J Fire Sci 32:374-387 